

\title{
ECONOMIA FEMINISTA, ECONOMIA SOCIAL E SOLIDÁRIA, PARADIGMA PARAECONÔMICO: REPENSANDO O PARADIGMA HEGEMÔNICO E A IMPORTÂNCIA DAS MULHERES
}

Feminist Economy, Social and Solidarity Economy, Paraeconomic Paradigm: Rethinking the Hegemonic Paradigm and the Importance of Women

Vanêssa Pereira SIMON

Universidade Federal de Santa Catarina (UFSC), Brasil vanessapsimon@gmail.com

\section{RESUMO}

O presente artigo tem como objetivo propor uma reflexão a respeito da imprescindibilidade de se reconfigurar o entendimento acerca do paradigma hegemônico, unidimensional, centrado no mercado. Para isso, reflete-se sobre a premência de se romper com os binarismos e as linhas divisórias da sociedade atual e o paradigma paraeconômico, ao propor uma análise multicêntrica, sem a predominância de nenhum dos enclaves que a compõe, apresenta-se como uma possibilidade. Deste modo, aproxima-se da economia feminista e da economia social e solidária por ambas entenderem a necessidade de se incorporar as atividades não mercantis e não monetárias a esse contexto. Especificamente, ambas trazem um destaque necessário para o papel das mulheres nessa reconfiguração paradigmática e, por conseguinte, a eliminação do viés androcêntrico atual.

PALAVRAS-CHAVE: Economia feminista. Economia social e solidária. Paradigma paraeconômico. Sociedade multicêntrica.

\begin{abstract}
This article aims to propose a reflection on the need to reconfigure the understanding about the hegemonic, onedimensional, market-centered paradigm. For this, it reflects on the urgency of breaking with the binarisms and dividing lines of the current society and the paraeconomic paradigm, when proposing a multicentric analysis, without the predominance of any of the enclaves that compose it, it is presented as a possibility. In this way, it approaches the feminist economy and the social and solidarity economy because both understand the need to incorporate non-market and nonmonetary activities in this context. Specifically, both highlight the necessary role of women in this paradigmatic reconfiguration and, therefore, the elimination of the current androcentric bias.
\end{abstract}

KEYWORDS: Feminist economics. Social and solidarity economy. Paraeconomic paradigm. Multicentric society.

Classificação JEL: B54

Recebido em: 12-02-2020. Aceito em: 12-05-2020. 


\section{INTRODUÇÃO}

A sociedade atual está configurada de maneira unidimensional, com a centralidade no mercado, valorizando o trabalho remunerado, público e majoritariamente produzido pelos homens em detrimento do trabalho privado, não remunerado e não monetário desenvolvido pelas mulheres. Isto é, uma sociedade dividida em linhas em que uns são tidos como superiores a outros, uns são considerados nas análises, em desvantagem de outros.

Faz-se, portanto, necessário rever esse paradigma hegemônico estabelecendo outro que contemple uma sociedade multicêntrica, que não nega a importância do econômico, porém não é moldada por ele. Imprescindível integrar às análises, questões normalmente desconsideradas como aspectos sociais, ecológicos, políticos. Portanto, serão primordiais as reflexões de Chanlat, Guerreiro Ramos e Boaventura Santos na reavaliação desse sistema prevalecente.

Ao se repensar o paradigma, um aspecto crucial a ser acrescido nessas análises é a questão das mulheres e sua atuação. No sistema vigente, o trabalho doméstico, de cuidado, de afeto, de reprodução e sustentação da vida, que é desenvolvido pelas mulheres no ambiente da casa, é invisibilizado. Assim, as discussões da economia feminista serão imprescindíveis para essa reavaliação do paradigma atual, principalmente pelas análises desenvolvidas sobre a invisibilidade em Sprecht, a sustentabilidade da vida em Carrasco e em Teixeira, o trabalho doméstico e de cuidado em Nobre e em Quintela, entre outras autoras que se dedicaram a desenvolver o tema.

Como outra linha de frente nesse enfrentamento ao paradigma posto, encontra-se a economia social e solidária que traz, em seus fundamentos, a solidariedade em oposição ao individualismo utilitário dominante no sistema atual centrado no mercado. Incorpora valores sociais, políticos e ecológicos em seus preceitos e estrutura-se de maneira mais igualitária em que todos têm o mesmo espaço e as mesmas possibilidades. Assim, tornase uma importante aliada para a economia feminista ao possibilitar retirar a invisibilidade das mulheres em seus empreendimentos ao considerar, e se embasar, em valores mercantis, mas também não mercantis e não monetários, como mostram os estudos de Guérin, Aguayo e Ramírez, Nobre e Faria, Hillenkamp, Verschuur entre outras. Importante destacar que este trabalho se insere em uma linha de investigação, já bastante consolidada, que objetiva mostrar as confluências entre as abordagens da economia 
feminista e da economia social e solidária, como pode-se observar nos estudos das autoras anteriormente citadas, além de Nobre, Matthaei, Díaz.

Ao longo do trabalho, portanto, a necessidade de reavaliação do paradigma vigente, principalmente de maneira a tirar a centralidade do aspecto econômico em favor de outros componentes da sociedade, será demonstrada e a consequência disso - que é o ponto chave aqui -, é que, ao repensar o paradigma, as mulheres ganharão uma visibilidade até então não possibilitada. Por conseguinte, o objetivo deste trabalho, é aproximar a economia feminista, com suas críticas ao comportamento androcêntrico do paradigma corrente com a economia social e solidária, com seus valores mais igualitários, e a ideia do paradigma paraeconômico como enfrentamento da sociedade unidimensional.

Para isso, o trabalho está dividido em 05 partes sendo a primeira esta introdução, seguida de uma reflexão sobre o paradigma paraeconômico com uma visão de sociedade multicêntrica em que o mercado ocupa um espaço, porém não é o centro estruturante, com valorização de aspectos diversos em contraposição ao paradigma hegemônico centrado no mercado e, consequentemente, estruturando as análise das atividade a partir do contraponto econômico, desconsiderando outros aspectos como questões sociais, culturais, ecológicas e de gênero. Na sequência, há uma explanação sobre a economia feminista e sua maneira de perceber o trabalho feminino para além do aspecto puramente econômico, mas considerando as atividades de cuidado, afeto e reprodução e o impacto disto para a sociedade. Em seguida, reflete-se sobre como a economia feminista se relaciona com a economia social e solidária com seus princípios de solidariedade, cooperação, que entende que o trabalho vai além do mercantil e contempla o não mercantil e o não monetário, aproximando-se assim, do entendimento da economia feminista e, logo, apresentando-se com um espaço proveitoso para atuação das mulheres. E, por fim, algumas considerações que contemplem essa necessidade de mudança paradigmática em sintonia com a economia feminista e a social e solidária face a proximidade de entendimento da sociedade com seu caráter multidimensional, benfazejo para a atuação das mulheres, bem como uma alteração no entendimento de seu papel na sociedade e assim sendo, da economia. 


\section{REFLEXÕES PARADIGMÁTICAS}

O pensamento moderno ocidental tende a estabelecer distinções visíveis e invisíveis em que as invisíveis são moldadas para fundamentar as visíveis, afirma Boaventura de Sousa Santos (2010). Para que isso se estruture, é necessário criar o que chama de "linhas" que dividem a sociedade entre "um lado da linha" e "outro lado da linha" e que essa divisão torna o "outro lado da linha" inexistente, não se apresentando de maneira relevante e, consequentemente, excluído, pois é exterior ao universo considerado válido pelo "um lado da linha”. E, continua, os dois lados não coexistem, pois um lado só se configura quando exaure as possibilidades relevantes do outro, para "além [...] há apenas inexistência, invisibilidade e ausência não-dialética" (p. 32). Aprofundando o raciocínio e estendendo-o em relação à humanidade, o autor afirma que "a negação de uma parte da humanidade é sacrificial, na medida em que constitui a condição para a outra parte da humanidade se afirmar enquanto universal” (p. 39). Com isso, trazendo para as análises econômicas, infere-se que, para que houvesse a predominância do modelo econômico hegemônico atual, alguns aspectos/sujeitos foram alçados à condição de relevância nesse cenário - "um lado da linha"- em detrimento de outros aspectos/sujeitos - "outro lado da linha", quais sejam os homens, "objetivos", trabalhadores no mercado, em prejuízo das mulheres, "sentimentais", com seus trabalhos desconsiderados seja em casa, seja em tarefas inferiores por não fazerem parte da estrutura predominante.

Em um outro plano de análise, Alberto Guerreiro Ramos (1989) afirma que nas sociedades pré mercado sempre houve uma distinção entre atividades/ocupações superiores e inferiores e que, a despeito das variações de uma sociedade para outra, duas características permeavam essa distinção. As atividades tidas como superiores são, preferencialmente, exercidas de maneira independente pelo indivíduo de acordo com seu desejo de realização pessoal, ou seja, ao exercer essas atividades, o sujeito realiza algo que perante os demais é desejável como um fim em si mesmo. As atividades que não atingem essa categorização de superior são normalmente, determinadas por necessidades objetivas e não pela escolha pessoal, com isso, forçam o indivíduo a se dedicar a esforços que não são intrinsecamente gratificantes.

A consolidação do sistema de mercado fez com que as atividades apresentadas como superiores se caracterizassem em trabalho (este que antes era tido como atividade menor - vide Aristóteles). Algumas razões apresentam-se para explicar esse movimento. 0 
sistema de mercado, a partir da revolução industrial, passa a exercer um comando sobre a vida social, pois a indústria tornou-se peça fundamental nesse sistema. Com isso, as habilidades pessoais passam para segundo plano, com prevalência das determinações mecânicas necessárias para se atingir os resultados esperados. Assim, o homem passa a ser considerado um componente da força de trabalho, de indivíduo a trabalhador no plano mecânico de produção. Porém, como a sociedade está regulada por esse sistema, o homem trabalhador passa a ter relevância nesta sociedade, ou seja, desempenha uma atividade "superior", desejada pelos seus pares (GUERREIRO RAMOS,1989).

Além disso, o sistema de mercado tem em seu cerne o conceito de valor monetário, utilizando tal parâmetro para determinar a equivalência entre bens e serviços. $O$ indivíduo faz parte desse processo de produção, mas como um item de custo e, logo, com um salário. Outro aspecto a se considerar é que o sistema de mercado não trata apenas de aspectos técnicos e econômicos e, por conseguinte, apenas conseguiu tornar-se o mais importante setor social na medida em que o processo de socialização induziu os indivíduos a assimilarem seus aspectos psicológicos. Contribuíram para isso diversos filósofos, religiosos ao longo do tempo e, como consequência, estabeleceu-se "a ética do trabalho, baseada no postulado de que o trabalho é o critério cardinal de valor, nos domínios da existência individual e social” (GUERREIRO RAMOS,1989, p. 133).

O trabalho então, passa a ser a medição do valor e da dignidade humana como forma de consolidar o sistema de mercado e minimizar a dissonância cognitiva em relação aos pensamentos pré mercado, assumindo assim, as características de atividade superior ao potencializar a realização de algo desejável perante os demais indivíduos de uma sociedade.

Com isso, podemos retomar Boaventura Santos (2010) entendendo que se criou uma linha entre aqueles que trabalham, desenvolvem uma atividade superior e estão "de um lado da linha" e aqueles que não trabalham, desenvolvem apenas atividades inferiores e, consequentemente estão "do outro lado da linha", invisíveis para essa sociedade centrada no mercado.

Como contraponto a esse panorama, Guerreiro Ramos (1989) propõe reexaminar o caráter unidimensional predominante nas análises das ciências administrativas, econômicas, políticas e sociais em relação aos sistemas sociais, uma vez que estes consideram, em sua maioria, o mercado como ponto de referência para a organização das questões pessoais e sociais. O autor delineia um modelo multidimensional para analisar os sistemas sociais com uma visão multicêntrica da sociedade que compreenda aspectos 
políticos, econômicos, culturais e psicológicos. Assim, haveria uma variedade de enclaves, em que o mercado seria um deles, mas não o mais relevante, uma vez que seria limitado e regulado, provendo, portanto, opções diferentes de atividades substantivas. Guerreiro Ramos (1989) não nega a importância do enclave econômico - que considera legítimo e necessário -, apenas questiona a primazia deste sobre os demais.

Guerreiro Ramos (1989), reiterado posteriormente por Yara Bulgacov e Felipe Castiglia (2003), assegura que a racionalidade instrumental, característica dessa sociedade de mercado, influencia sobremaneira o sujeito, visto como o resultado de um cálculo utilitarista, típico desse mercado. Consequentemente, a sociedade atualmente, é modelada pelos padrões do mercado. O indivíduo, nesta sociedade, tem a ilusão de ganhos materiais, porém não percebe a perda do senso pessoal de autorrealização. E, como realça Geyson Araújo (2010), nessa análise, Guerreiro Ramos entende que o mercado é uma economia entre outras e, dessa maneira, não seria prudente universalizar seus conceitos para outros tipos de economia, como a não mercantil e a não monetária.

Esse modelo multidimensional estabelece, como noção central, a delimitação organizacional - com uma visão de sociedade constituída de vários enclaves onde o sujeito engaja-se em atividades substantivas diferentes, porém que se integram; e de um sistema de governo social - que implemente políticas distributivas para a melhor integração entre os enclaves sociais. Critica ainda o modelo tradicional de uma sociedade centrada no mercado e propõe que se considerem questões importantes como ecologia e o lado psicológico do indivíduo, de maneira a assegurar que não se reproduzam os impactos negativos para a sociedade desse foco no mercado. Além disso, nesse modelo, o mercado é um enclave dentro de uma realidade social multicêntrica, com múltiplos critérios substantivos para uma vida pessoal, além de uma gama de possibilidades de relações interpessoais. Sendo assim, o indivíduo tornar-se-á um maximizador de utilidades apenas incidentalmente, porque despende todo o esforço no sentido de organizar sua existência em consonância com suas necessidades de autorrealização pessoal. Nessa perspectiva, o sujeito não se vê obrigado a conformar-se plenamente com os valores do mercado, de maneira que encontre ocupações e que participe de outros espaços, que não o mercado, para superar o processo contínuo de unidimensionalização da vida individual e coletiva (GUERREIRO RAMOS, 1989; BULGACOV, CASTIGLIA, 2003; PAULA, 2007).

Como maneira de ilustrar esses sistemas sociais, Guerreiro Ramos (1989) concebe o que denomina "paradigma paraeconômico", ou seja, um modelo multidimensional da existência humana, numa visão multicêntrica de sociedade, em que cada dimensão são 
tipos ideais weberianos, pois, na realidade, sistemas sociais são mistos, porquanto a imbricação entre esses sistemas inviabiliza a possibilidade de um sistema isolado, que não influencie, mas que é influenciado pelos demais. Ana Paula Paes de Paula (2007) elenca alguns pontos básicos da obra de Guerreiro Ramos importantes para a compreensão do paradigma paraeconômico: a crítica à sociedade dominada pelo ethos do mercado; a análise da síndrome comportamentalista, que dificulta a percepção do indivíduo como centro e objeto dos sistemas sociais; a crítica do mercado enquanto maneira de compreender a realidade social; e a bidimensionalidade do conceito de racionalidade. Porém, esses pontos não serão aprofundados por não serem objetos desse trabalho, apenas informações relevantes para o entendimento do paradigma.

O paradigma paraeconômico apresenta duas orientações (figura 01): a comunitária em contraposição à individual; e a prescrição contra a ausência de normas. Na primeira orientação, há a preocupação de que seja um modelo suficientemente amplo para não reduzir o indivíduo a um mero agente de maximização de utilidade, o indivíduo não é obrigado a conformar-se plenamente com o sistema de valores do mercado, há um cuidado com o espaço para a autorrealização pessoal. No segundo caso, procura mostrar que a relação entre prescrições operacionais e autorrealização pessoal é inversamente proporcional, porém entendendo que não há como se eliminar as prescrições do mundo social, pois são elas que mantêm e desenvolvem um sistema de apoio de uma coletividade. São essas prescrições que acabam por conformar a sociedade e também os indivíduos que a compõe, que passam a se comportar de maneira mecanomórfica, de acordo com essas prescrições e perdem, muitas vezes, a sua capacidade de agir de maneira consciente e deliberada. Contudo, necessita-se delimitar os enclaves que cabem nessas prescrições (GUERREIRO RAMOS, 1989; FRANÇA FILHO, 2010).

Além disso, Guerreiro Ramos (1989) ressalva que, assim como devem ser entendidos como tipos ideais, não se pode esperar que existam de maneira segregada no espaço físico. Caracterizam-se por seus estilos inerentes de vida e, ocasionalmente, em vizinhança física. O paradigma considera os espaços onde as prescrições impostas praticamente não acontecem e, também, ambientes pequenos e singulares como ambientes comunitários; e de tamanhos regulares, adequados às necessidades de autorrealização pessoal (AZEVEDO, ALBERNAZ, 2004). 
Figura 1 - Paradigma Paraeconômico

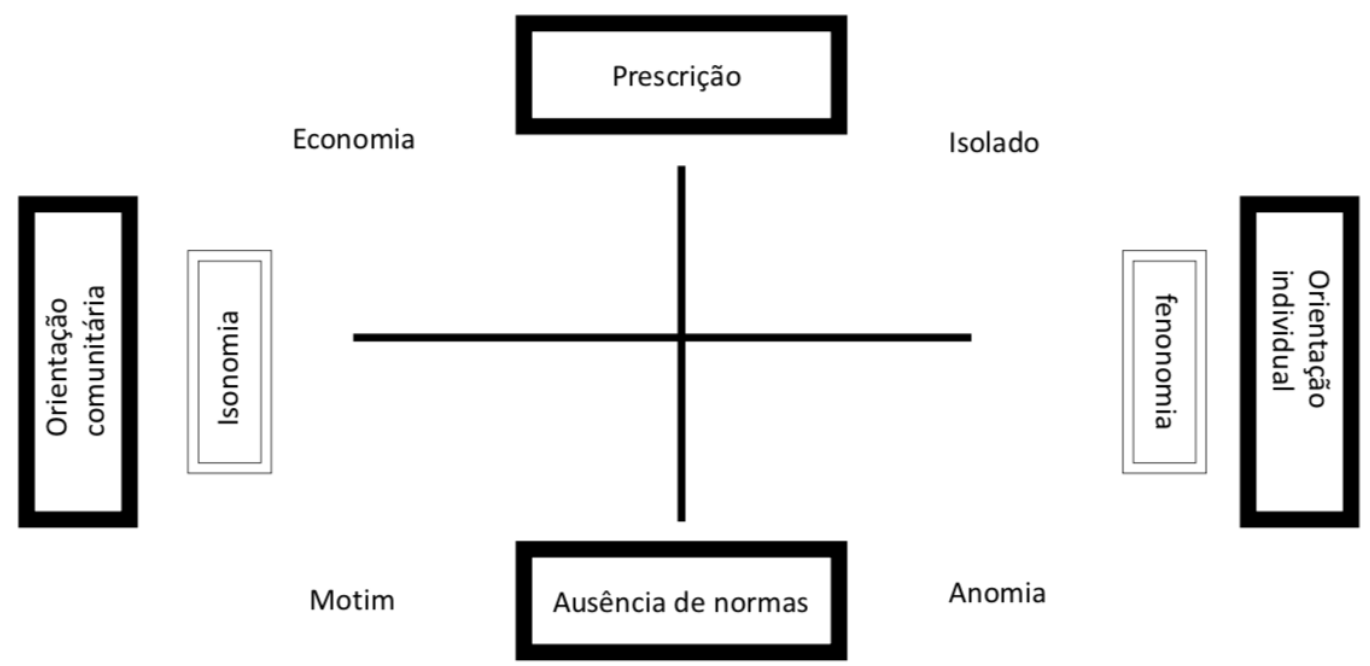

Fonte: Guerreiro Ramos (1981, p. 141).

O paradigma paraeconômico assim, caracteriza-se como uma possibilidade de ruptura das "linhas" ao apontar para a necessidade de se considerar os outros muitos aspectos de uma sociedade, que não apenas o econômico, e dar visibilidade portanto, para demais atores e formas organizacionais, sem se restringir ao mercado e aos atores destacados por ele.

Retomando, o discurso construído, principalmente a partir da revolução industrial, orienta para um pensamento único. Como afirma Jean-François Chanlat (1999), o pensamento econômico hegemônico em nossa sociedade é baseado na lógica do capitalismo, propriedade privada, interesses pessoais, busca incessante pelo lucro e de acumulação. Com isso, o espaço de excelência se tornou o de mercado e, consequentemente, o da empresa - "fonte de riqueza e de cultura, destinada a resolver a maioria dos problemas com que nos defrontamos hoje" (p. 16).

E quem é o representante perfeito dessa sociedade em que o mercado é o centro? Aquele que foi desde o início, deslocado para esse espaço - homem, adulto, branco, heterossexual, civilizado, do "primeiro mundo". François Belle (2010) afirma que a mulher sempre esteve presente, desde o início da industrialização, porém com um trabalho menos qualificado, mal remunerado, e quase nunca em posição de tomada de decisão/poder, pois tinha que se ater primeiramente, ao seu papel de mãe, esposa - papeis reconhecidos e 
legitimados pela sociedade. A indústria não foi feita nem por ela, nem pensando nela, é um mundo de homens. E, em conformidade com o pensamento de Boaventura Santos (2010), ao assumir o papel "do outro lado", assimila o papel "natural" de assalariada subqualificada, e com isso, assegura ao homem sua identidade e permite que ele alimente sua superioridade social, graças à dominação que exerce no mundo profissional.

Quando o mundo é estruturado a partir da lógica de mercado, como afirmam Guerreiro Ramos (1989), Chanlat (1999) e Boaventura Santos (2010), o papel da mulher passa a ser o de invisibilidade, aquele que existe para sustentar o papel principal da atividade superior, "de um lado da linha", ou seja, o trabalho doméstico, de cuidado, o afeto, a reprodução - a sustentação da vida, não mercantil e não monetária. Em consonância com esse tipo de análise, a economia feminista vem discutir a invisibilidade da mulher para a economia hegemônica, mais precisamente, a invisibilidade do trabalho desenvolvido por elas em casa e no cuidado da família.

\section{ECONOMIA FEMINISTA E ECONOMIA SOCIAL E SOLIDÁRIA: "OUTRAS ECONOMIAS"}

\subsection{Economia Feminista}

Primeiramente, é necessário resgatar a origem do termo economia em Aristóteles: oikos (casa, lugar) e nomia (regras, normas da casa, do lugar), ou seja, o cuidado da casa, como afirmam Sandra Quintela (2006) e Analine Specht (2009). Com isso, a casa, ou o ambiente privado de produção e reprodução, remete ao espaço que atualmente é desconsiderado na noção hegemônica de economia e, consequentemente, o papel de quem prioritariamente desenvolve seu trabalho nesse espaço - as mulheres. Sendo assim, os economistas, a partir desse conceito, deveriam considerar o trabalho elaborado pelas mulheres como basilar. Entretanto, como desenvolvido anteriormente, o mundo estruturouse com a centralidade no mercado, na monetarização das trocas e no papel de destaque para aqueles que ocupam esses espaços, na noção de indivíduo que busca a maximização de interesses particulares, motivados prioritariamente pelo lucro (homo economicus). O espaço das trocas não monetárias, dos cuidados da casa, dos filhos, dos idosos, do emocional, da agricultura familiar tornou-se invisível nos estudos e nas discussões sobre o mundo do trabalho (QUINTELA, 2006; SPECHT, 2009; GRECCO, 2018). 
A crítica a essa noção de economia pela chamada economia feminista inicia-se a partir dos anos 1960/70, examinando, tanto o paradigma neoclássico quanto o marxista, e a maneira como apresentam a situação socioeconômica das mulheres, afirma Cristina Carrasco (1999). Na economia neoclássica, o papel tradicional definido para ambos os sexos, quer seja na família quer seja no mercado, reitera a conjuntura existente, ou seja, aos homens competem o trabalho público, remunerado, valorizado pelo mercado, enquanto para as mulheres são delegadas basicamente, as tarefas não remuneradas, privadas, invisíveis para o mercado. No marxismo, por outro lado, as noções de proletariado, exploração, produção e reprodução são encaradas com uma neutralidade em relação ao gênero, como se houvesse uma confluência natural de interesses econômicos entre homens e mulheres da classe trabalhadora. Além de que o trabalho doméstico (predominantemente feminino) não remunerado, não faz parte do movimento circular do valor de troca e, portanto, é improdutivo. Ou seja, ambas as vertentes tratam historicamente a divisão por sexo no trabalho e na família como se fosse uma determinação biológica (CARRASCO, 1999; QUINTELA, 2006).

Fabiana Grecco (2018), em uma análise do desenvolvimento da economia hegemônica desde a mão invisível de Adam Smith, afirma que o sujeito delineado no paradigma dominante é fundamentalmente centrado nele mesmo, racional, tecnicamente autossuficiente, sem gênero, classe, etnia, porém relacionado, ao longo do tempo, ao homem branco, hétero, das classes sociais dominantes, preocupado essencialmente com o lucro, ou seja, a sociedade entendida como restrita ao mercado (centralidade no mercado/unidimensional). Ademais, a economia feminista ressalta que não há uma autonomia para exercer as escolhas, como alega a tendência predominante, uma vez que há relações de poder e conflito, tanto na sociedade como na família, fazendo com que uns tenham mais autonomia que outros. Além de difundir o mito da independência, "o pressuposto da autonomia esconde todo o trabalho da reprodução, da produção das pessoas, que é feito em sua maioria pelas mulheres" (NOBRE, 2002, p. 2). Ou seja, esse homo economicus apenas pode existir como sistema econômico predominante porque as suas necessidades básicas de toda ordem - físicas, emocionais, individuais, sociais - são garantidas pelo trabalho não remunerado das mulheres. Portanto, seriam estes trabalhos invisibilizados, não remunerados que sustentariam o conjunto da sociedade, surgindo inclusive a figura da "dona de casa" disponível para os trabalhos domésticos, subproduto do trabalho produtivo, num pensamento claramente androcêntrico e centralizado no mercado (CARRASCO, 1999; GRECCO, 2018). 
Este comportamento é fruto da universalização da ideia de que o que é público, mercantil, econômico e racional é naturalmente, pertencente ao masculino, destinando às mulheres, à esfera privada, doméstica, de reprodução, não necessariamente monetária/mercantil. Assim, a reprodução social - que compreende os trabalhos que se ocupam da reprodução da vida (trabalhos domésticos e de cuidados) - são considerados trabalhos improdutivos ou não mercantis e, dessa maneira, tendem a ser invisibilizados e negligenciados. Esta invisibilidade do trabalho doméstico nas análises econômicas fez com que também a economia não monetária fosse invisibilizada no pensamento econômico. Como afirma Marilane Teixeira (2018), a economia monetária depende da economia não monetária, uma vez que os salários que normalmente são recebidos pelas famílias não são suficientes para dar conta de todos as necessidades familiares. Isso faz imprescindível o trabalho do âmbito doméstico e das relações afetivas e emocionais, que não são adquiridas no mercado, porém são essenciais para o pleno desenvolvimento do ser humano. Isto é, resgatar o sentido primeiro da palavra economia (oikos; nomia), o cuidado da casa, do privado, de produção e reprodução.

É importante avaliar que para haver produção é preciso considerar a necessidade da reprodução da força de trabalho, ou seja, não é possível negligenciar esse aspecto da economia. O trabalho das mulheres realizado no interior das residências tem valor econômico - o que não quer dizer valor monetário. É econômico ao criar condições para que outros seres (homens e mulheres) vendam sua força de trabalho numa sociedade centrada no mercado, porém invisível ao não constar em dados estatísticos ou contábeis (SPECHT, 2009; GRECCO; FURNO; TEIXEIRA, 2018).

Reforçando, não se consegue perceber o comportamento econômico das mulheres e suas atividades, pelo caráter androcêntrico dado à economia pelos pesquisadores (CARRASCO, 1999; NOBRE, 2002; QUINTELA, 2006). Esse pensamento é robustecido pelos economistas tradicionais ao darem um maior enfoque para áreas como comércio e governo, em detrimento de áreas relacionadas à equidade social e econômica (TEIXEIRA, 2018).

De maneira geral, percebe-se que as mulheres não têm sido totalmente esquecidas, mas são consideradas, implícita ou explicitamente, como exceções às regras, alheias à esfera econômica e com uma participação marginal nas atividades econômicas nacionais. Há uma tradição em ignorar a divisão sexual do trabalho e ocultar o trabalho familiar doméstico e sua articulação com o sistema hegemônico, mantendo uma rígida separação entre as dicotomias público e privado, razão e sentimento, trabalho mercantil e trabalho 
doméstico, empresa e família. O que se compreende é que, apesar de a contribuição econômica das mulheres para a reprodução familiar ser decisiva, isso ocorre de maneira invisível aos olhos da maioria dos pensadores clássicos da economia. Basicamente, porque o emprego feminino é considerado circunstancial e complementar ao masculino, uma vez que a responsabilidade primordial da mulher é o lar. Entende-se que por ser a mulher considerada responsável pelo cuidado dos filhos, por exemplo, elas têm, muitas vezes, que fazer uma "escolha", optando assim, por trabalhos informais, ou com jornadas reduzidas para conciliar o emprego e o cuidado da casa/filhos. Assim, apesar de qualificadas, preparadas para o desempenho de suas funções, suas habilidades são desconsideradas, naturalizadas quando da remuneração de seus trabalhos. Ou seja, a decisão das mulheres participarem ou não do mercado de trabalho muitas vezes é vista como uma escolha de maximização de resultados, sem considerar as relações sociais de sexo que ocorrem no interior das famílias e da sociedade na dinâmica entre produção econômica e a reprodução social, basilares nesse sistema prevalecente (CARRASCO, 1999; NOBRE, 2002; TEIXEIRA, 2018).

Mirian Nobre (2002, p. 2) afirma que a economia feminista estrutura-se para

[...]tornar visível a contribuição das mulheres à economia. São pesquisas que consideram o trabalho de forma mais ampla, incluindo o mercado informal, o trabalho doméstico, a divisão sexual do trabalho na família, e integram a reprodução como fundamental à nossa existência, incorporando saúde, educação e outros aspectos relacionados como temas legítimos da economia.

A importância de economia feminista está em ressaltar o ponto de vista político e assim, dar um caráter mais objetivo e menos omisso, revisando os conceitos da economia tradicional, a partir das críticas da economia feminista, ao considerar aspectos éticos e morais de igualdade de gênero, nas esferas produtivas e reprodutivas e nas relações existentes tanto dentro delas como entre estas esferas (FERNANDEZ, 2018; GRECCO; FURNO; TEIXEIRA, 2018).

Para Grecco (2018), a neutralidade da pesquisa econômica pode ser questionada pelos valores e interesses androcêntricos que estabeleceram os conceitos e métodos de análise, excluindo, das investigações locais, os socialmente marginalizados como os trabalhos domésticos e de cuidados e outros pontos de vista, como o feminista que se propõe a analisar criticamente esses pressupostos e interesses. Assim, a ideia tradicional de ciência objetiva, neutra e distante das subjetividades dos cientistas é analisada pela economia feminista como reprodutora (ou no mínimo negligente) de desigualdades 
instigadas pelos conflitos das relações sociais entre os gêneros. O viés androcêntrico do saber científico presente nas interpretações de dados e resultados, na escolha dos temas ocorrem numa perspectiva que acaba por universalizar as normas e valores de uma cultura construída pelo domínio masculino. Mesmo as políticas públicas direcionadas às mulheres são normalmente sociais e raramente econômicas, ou seja, há um reforço no pensamento de que as mulheres não têm relação com os processos macroeconômicos. $O$ trabalho profissional das mulheres é normalmente visto como complementar às responsabilidades domésticas, o que acaba por consolidar o pensamento hegemônico (CARRASCO, 1999; PESSOA; RAMOS; PEIXOTO, 2004; QUINTELA, 2006; SANTOS, 2010).

Ao pensar a economia como um todo, há outros valores que fazem as pessoas se moverem e tomarem decisões que não somente a competição e a eficiência. A competição, assim como as desigualdades, não são algo natural entre as pessoas, são o resultado de como se organiza a vida social e econômica na sociedade (NOBRE, 2002; SANTOS, 2010).

Segue Grecco (2018, p. 126),

Para as economistas feministas, o dualismo cartesiano que distingue público/privado, mercado/família, homem/mulher, razão/ emoção, mente/corpo, história/natureza, objetividade/subjetividade, explica a origem histórica do homem econômico. [...] Isto é, na medida em que há historicamente uma separação entre o feminino mais relacionado à subjetividade e o masculino à objetividade, fica fácil perceber quais sujeitos e quais conjuntos de interesses são preteridos pela ciência "objetiva" por definição cartesiana. É desse modo que se caracteriza o viés androcêntrico da economia predominante: vai além do homo economicus, diz respeito à própria estrutura do fazer científico.

Teixeira (2018), dentro desse escopo da economia com viés feminista, afirma que existe uma vertente que enfoca gênero e economia que destaca as desigualdades entre homens e mulheres, porém a partir dos marcos analíticos estabelecidos, sem discuti-los. $\mathrm{E}$ outra vertente, a economia feminista propriamente dita, que destaca a necessidade de ir além desta dicotomia e de construir paradigmas mais adequados para uma análise socioeconômica mais integrativa, que contemple distintas atividades como os cuidados domésticos e a sustentabilidade da vida humana.

Corroborando esse pensamento, Grecco (2018) afirma ainda que para as economistas feministas não é suficiente simplesmente acrescentar as mulheres no contexto, é necessário estabelecer uma teoria em que as ferramentas analíticas sejam reinventadas com pressupostos e métodos que atentem para os trabalhos não considerados pela economia hegemônica como por exemplo, a produção do viver, a sustentabilidade da vida humana e que valores como emoções, responsabilidade com 
outros, reciprocidade, solidariedade, subjetividades sejam contemplados (GRECCO; FURNO; TEIXEIRA, 2018).

Dado o caráter crítico da economia feminista, dificilmente encontrar-se-á uma conceituação única, uma vez que participam das pesquisas e discussões pesquisadoras(es) das diversas escolas de economia, bem como das diversas tradições do feminismo. Assim, há a promoção de uma interdisciplinaridade principalmente, com a sociologia, antropologia, história, na tentativa de conseguir elaborar uma crítica à macroeconomia, às análises das políticas econômicas. Isto promove uma releitura da história do pensamento econômico, assim como a construção de novos métodos de pesquisa, com elaborações teóricas que reconheçam a importância do trabalho realizado pelas mulheres tornando visível as diversas atividades realizadas no recôndito da sociedade. Importante ressaltar, como abordado acima, que mesmo no interior da economia feminista diferentes abordagens coexistem, sem o pressuposto de uma dominação de uma em detrimento de outra, sem negar os possíveis conflitos teóricos/metodológicos (CARRASCO, 1999; QUINTELA, 2006; TEIXEIRA, 2018).

Uma vertente feminista que trata da sustentabilidade humana afirma que integrar uma nova esfera de atividade como casa, trabalho doméstico e reprodução não é o bastante, pois essas análises permanecem privilegiando a esfera do mercado e, com isso, deixam em segundo plano as esferas não econômicas. É necessário possibilitar que as relações sociais que permitam a satisfação das necessidades das pessoas (necessidades estas em constantes transformações) possam ser contempladas nas análises. Assim, entende-se que não há um sujeito unitário que caracterize a mulher no mundo, mas reconhece-se a diferença, as relações de poder inclusive entre as próprias mulheres (TEIXEIRA, 2018).

Entende-se que as necessidades humanas vão muito além de bens e serviços, passam essencialmente, por afetos e relações. Com isso, as características tidas como femininas, como o cuidado, devem ser reconhecidas e também valorizadas e não postas à margem das análises econômicas. Consequentemente, a noção de trabalho também precisa ser ampliada para além da esfera do mercado, incorporando todas as atividades que fazem parte do processo de sustentabilidade da vida humana. Não é suficiente, portanto, propor soluções para o trabalho doméstico de maneira a reforçar a dupla jornada ou soluções para a precarização do trabalho. É necessário alterar a lógica mercantil do sistema econômico preponderante, criando formas alternativas de se perceber o mundo (TEIXEIRA, 2018). 
Por outro lado, Brena Fernandez (2018, p. 561) ressalta que, com a inserção da mulher no mercado de trabalho, principalmente após as duas grandes guerras, algumas questões são postas e precisam ser refletidas pela economia:

Perguntas atinentes à possibilidade de participação no espaço público por parte das mulheres, à modalidade dos trabalhos desempenhados por elas, às suas ocupações típicas, às condições de estabilidade ou de intermitência destes trabalhos, aos seus salários, à existência ou não de diferenças entre as pautas laborais masculinas e femininas, à dupla jornada de trabalho, à tentativa de identificação de discriminação contra as mulheres no ambiente de trabalho, bem como aos modos como as diversas discriminações poderiam manifestar-se são algumas das questões pedra de toque para a economia dita feminista.

Consequentemente, continua a autora, essa inserção no mercado de trabalho remunerado passa a ter impacto no trabalho doméstico, não remunerado, desempenhado tradicionalmente por ela, o que suscita novos questionamentos para a economia hegemônica como a discussão sobre a valorização do trabalho remunerado em detrimento do não remunerado, bem como a divisão do tempo entre essas atividades, o que compromete prioritariamente as escolhas das mulheres.

Por isso, a necessidade da economia feminista se debruçar sobre tanto o trabalho remunerado quanto o não remunerado, o visível e o invisível, o público e o privado sem dar primazia para uns em detrimentos de outros - rompendo com o paradigma vigente.

Teixeira (2018, p.160) aponta quatro componentes fundamentais nas contribuições da economia feminista para a teoria econômica: i) dar visibilidade às mulheres como sujeitos, legitimando suas experiências e perspectivas; ii) reconhecer e entender as desigualdades entre mulheres e homens; iii) modificar a teoria, a metodologia e as práticas da disciplina econômica; e iv) desenvolver um método que inclua todas as pessoas. $E$, acrescenta que, ao focar na sustentabilidade da vida humana, a economia feminista apresenta-se como um expediente importante de análise, pois estabelece uma crítica global ao sistema hegemônico e, consequentemente à economia de mercado e, com isso, passa a ser incorporada pelos movimentos feministas, ganhando maiores dimensões. Ou seja, os grandes desafios para a economia feministas dizem respeito principalmente, à necessidade de reconceitualização dos paradigmas e métodos da economia hegemônica de maneira a se estimular um processo de alteração das relações sociais de gênero em prol de uma sociedade mais emancipada e igualitária, que considere saúde, educação e cuidados como aspectos relevantes e temas legítimos para a economia (SPECHT, 2009; FERNANDEZ, 2018). 
Portanto, afirma Fernandez (2018, p. 580)

Como o paradigma econômico tradicional se tem mostrado incapaz de tratar de forma adequada esta realidade, parece ter se tornado claro que o avanço do conhecimento científico na área econômica, aos moldes tradicionais, é insuficiente para atingir o projeto de desenvolvimento com justiça e emancipação social, a partir da concepção de equidade de gênero, objetivo este para o qual as quase três décadas de existência da economia feminista vem lenta, porém continuamente, prestando a sua contribuição.

Assim, é necessário repensar esse paradigma e, para isso, algumas aproximações com outras vertentes de análise se fazem pertinentes. É o caso da economia social e solidária.

\subsection{Economia Social e Solidária e Economia Feminista}

A economia social e solidária (ESS) possui diversas conceituações que estão sempre associadas à ideia de solidariedade em contraposição ao individualismo utilitarista largamente presente na sociedade atual, a sociedade de mercado, em que os recursos produtivos são socializados e os critérios adotados, de maneira geral, são mais igualitários, destacam Jean Louis Laville e Luis Inácio Gaiger (2009).

Porém, independentemente da conceituação adotada, o ponto comum, além da crítica à ciência econômica, é a ESS contemplar as dimensões sociais e ecológicas, ou seja, entende que a visão unidimensional - apenas o mercado - não se sustenta mais, afora que limita as potencialidades de criação de outras formas de riqueza que não são percebidas por essa lógica reducionista, afirmam Patrice Sauvage (1996), Noelle Lechat (2002) e Natalia Díaz (2009).

A ESS tem uma lógica distinta, tanto do mercado quanto do Estado, por se organizar a partir de fatores humanos, que favorecem as relações sociais por meio da reciprocidade ao adotar formas comunitárias de propriedade. Distingue-se da economia estatal, pois não prevê formas de propriedade institucional nem autoridade central e, novamente, a ênfase é evitar as separações entre o econômico, social e político, pois é na articulação desses três setores que se situa o essencial da ESS, que tenta dar conta de iniciativas da sociedade civil que não se encaixam no que está legalizado (LECHAT 2002).

O modelo atual de ESS surge ao mesmo tempo que o feminismo, a agroecologia e o revigoramento da agricultura familiar num contramovimento de defesa da sociedade em relação à hegemonia do mercado, como parte de uma transição paradigmática e civilizatória 
sintonizada com novas formas de possibilidades organizacionais. O diferencial da ESS está na ideia de solidariedade não como mero adjetivo, mas dando forma à nova lógica econômica que incorpora o social. É a economia não separada das dimensões culturais, políticas, éticas, com autonomia, sem privar do caráter substantivo, destaca Armando Lisboa $(2003,2009)$.

Em termos econômicos, a ESS congrega uma série de empreendimentos que contemplam diversas relações econômicas como doação, reciprocidade, cooperação de múltiplas formas, mas, independentemente da forma adotada, os fundamentos éticos e solidários estão presentes. Na vertente política, há uma busca por emancipação ao reunir o trabalhador com o proprietário dos meios de produção, bem como o trabalho intelectual e manual, os bens econômicos e as necessidades humanas, por meio de uma gestão mais democrática dos empreendimentos (AGUAYO; RAMÍREZ, 2019). Acrescentam Cleudes Pessoa, Jeanette Ramos, Socorro Peixoto (2004, p. 9) que a construção de um empreendimento autogestionário instiga homens e mulheres a

[...] desconstruir valores individualistas e estabelecer relações solidárias, pautadas nos seguintes valores: democracia - decisões tomadas pelo conjunto dos associados e associadas; participação - garantia do direito de decidir e condições para a efetiva participação; igualdade - todos/as têm tratamento igualitário, seja de remuneração, como de acesso à formação e conhecimento, para mesma tarefa e função; cooperação - responsabilidade partilhada na gestão e produção; desenvolvimento humano - concepção da formação como direito de todo/a trabalhador e trabalhadora, numa dimensão humana que possibilite o acesso às novas técnicas e educação integral. Valores estes que buscam o fim de toda e qualquer forma de exclusão/discriminação.

Percebe-se uma aproximação entre os conceitos da ESS e da economia feminista uma vez que ambas se propõem a repensar as relações econômicas e sociais, a partir de valores para além do monetário e, com isso, reconfigurar o pensamento econômico (QUINTELA, 2006; SPECHT, 2009; SANTOS, 2010; NOBRE, 2014). Acrescenta Nobre (2015) que um diálogo entre análises e práticas da econômica feminista e da ESS permite superar as fragmentações entre produção e reprodução, e as questões políticas das econômicas no que chama de "economia política da resistência".

Beatriz Aguayo e Loreto Ramírez (2019) alegam que essa aproximação abre possibilidades políticas e econômicas: para a economia feminista, ao fazer as atividades domésticas tornarem-se públicas, valiosas e políticas e para a ESS, ao possibilitar um outro espaço econômico para a discussão política. Acrescentam as autoras que a economia 
feminista fez um amplo exercício de desvendar os preconceitos androcêntricos subjacentes à economia como disciplina e que, de certa forma, se estende para a economia social e solidária, o que faz com que essa aproximação seja bastante profícua. Assim, a resolução coletiva na esfera pública de necessidades anteriormente circunscritas à esfera privada constitui uma importante possibilidade e um intersecção relevante entre a ESS e a economia feminista.

Na ESS, os princípios predominantes contrapõem-se aos princípios dominantes na sociedade atual que acabam produzindo desigualdades econômicas, mas também sociais, culturais e, por que não, de gênero. Estas desigualdades, é importante destacar, não são naturais, são resultados da maneira como a vida social e econômica se organiza na sociedade - são construções culturais (NOBRE, 2002; SANTOS, 2010).

A matriz cultural que estabeleceu essas desigualdades, com rebatimento na subordinação das mulheres aos homens, estende-se às esferas públicas e privadas e faz a distinção clara da superioridade masculina física, mental e espiritual em relação à inferioridade das mulheres, afirma Graciete Santos (2010). Essa matriz foi construída tanto pelas religiões, quanto pela filosofia e ciência que argumentaram, em seus pressupostos, que o homem era portador do princípio da vida e, portanto, merecedor das condições de superioridade.

Em contraposição a esse pensamento, Isabelle Guérin (2005, p. 12) declara que a ESS "é uma resposta possível, [ao sistema hegemônico] tanto do ponto de vista conceitual como do operacional", uma vez que as "mulheres são frequentemente as primeiras atrizes da economia solidária; mas o mais importante (...) oferecem uma oportunidade inédita para avançar na luta contra as desigualdades entre os sexos". A partir da participação na ESS, as mulheres têm tido a possibilidade de perceberem-se como atuantes, de fato, e de mostrar seu potencial econômico ao romper com vários estigmas sobre a mulher que trabalha (PESSOA; RAMOS; PEIXOTO, 2004). Daí a necessidade de analisar o papel das mulheres nesse movimento que se apresenta como um espaço de equidade, pelos seus preceitos, bem como verificar oportunidades e problemas apresentados e, novamente, a aproximação com a economia feminista se faz indispensável.

Seguindo na reflexão sobre a ESS, há uma característica peculiar, a oferta ocorre juntamente com a demanda: os serviços são concebidos e propostos em razão de necessidades sociais reais e locais. Não é a lógica de rentabilidade do capital investido, mas a realização de desejos legítimos dos grupos locais por causa da interação entre os diferentes participantes desta iniciativa. Associa a ideia de iniciativa e solidariedade ao 
inserir a noção de solidariedade no meio das atividades coletivas econômicas, ressalta Genauto França Filho $(2002,2003)$. Nobre (2015) acrescenta que a ESS, pelos seus princípios, propõe uma ressignificação do trabalho em razão do que ele proporciona enquanto crescimento pessoal e não pelo seu valor mercantil ou de troca e também, a estruturação da atividade econômica com uma racionalidade particular que associa o empreender com a solidariedade. Ao que acrescenta Días (2009, p. 85, tradução nossa) que "essas visões de ESS compartilham a necessidade de privilegiar os valores de uso em detrimento do valor de troca, o que implica valorizar bens e serviços por sua contribuição à reprodução das comunidades, e não pelos mecanismos mercado capitalista habitual".

Com isso, valoriza-se as necessidades coletivas e o cuidado do outro e valorizar esse cuidado é uma ação política por não entender que essa atitude é um atributo naturalizado feminino, nem restrito ao espaço da família, ou seja, é necessário que o coletivo seja responsabilizado, bem como uma distribuição igualitária das tarefas em todos os espaços. A ESS pode contribuir com esse debate trazido pela economia feminista uma vez que se preocupa com a satisfação das necessidades das pessoas e não apenas pelo caráter mercantil (NOBRE, 2003; SPECHT, 2009).

Assim, a ESS ao trabalhar com recursos mercantis, não mercantis e não monetários reconhece e valoriza as relações de confiança e reciprocidade nas relações de trabalho. $\mathrm{Na}$ sociedade atual, essas relações de reciprocidade são mantidas basicamente, pelo tempo que as mulheres se dedicam a elas. Isto não pode ser mensurado pelos parâmetros de mercado, porém são essenciais na organização dos empreendimentos solidários (SPECHT, 2009). Reiterando esse pensamento, Arroyo e Ramírez (2019) afirmam que o sistema baseado no mercado apresenta-se como uma possibilidade econômica, porém não considera uma série de relações econômicas não monetárias, nem mercantis que não são sopesadas e que ocupam boa parte do universo econômico e que são chaves para a reprodução da vida e do bem-estar da sociedade, como já apresentado anteriormente.

A economia feminista por sua vez, pode colaborar com a ESS, de acordo com Specht (2009), ao propor o fim da distinção entre atividades mercantis e não mercantis e a valoração das atividades de subsistência humana e, por conseguinte, entender a desvalorização dada ao aspecto da reprodução e das atividades correlatas a isso, consideradas inferiores, secundarias, efêmeras. Assim, a noção de trabalho também passa a ser ampliada para além do entendimento tradicional de trabalho produtivo, mercantil. Esta ampliação, ao considerar a totalidade das formas de trabalho, contribui efetivamente, para uma igualdade das atividades realizadas e, também, uma igualdade de quem as realiza. 
Assim, o trabalho das mulheres, tido muitas vezes como improdutivo, ganha nova configuração nesse cenário, ou seja, o trabalho doméstico e de cuidados é estruturado numa "racionalidade substantiva, não monetária e desmercantilizada" (AGUAYO; RAMÍREZ, 2019, p. 5).

Aprofundando esse pensamento, a ESS, por sua vez, ao não fazer distinção entre proprietários e empregados, ao entender que todos têm igual possibilidade de desenvolver suas atividades e ser remunerados, ao possibilitar a participação de todos nos espaços coletivos sem distinção, surge como uma alternativa para o rompimento da dicotomia entre a valorização do trabalho do homem em relação ao trabalho, tido como inferior, realizado pela mulher. Ao propor novas práticas de gestão e logo, uma cultura de trabalho distinta em relação a como se produz e como se consome pode ser percebida como um campo de experimentos de relações não hierárquicas, o que fortalece a autonomia. A ESS permite, assim, ampliar a noção de trabalho, ao qualificar esse conceito e entender que não existe um trabalho emancipado se não houver uma real divisão das tarefas domésticas entre todos que convivem no mesmo espaço (NOBRE, 2003; GUÉRIN, 2005; DÍAZ, 2009; SANTOS, 2010; AGUAYO, RAMÍREZ, 2019).

Porém, entende-se que as organizações da ESS estão inseridas em uma sociedade com valores hegemônicos e, portanto, não estão isentas de absorverem esses valores e assim, há que se tomar cuidado para que não acabem perdendo sua identidade ao passar a reproduzir esses comportamentos discriminatórios, pois isso fere seus princípios fundamentais. As organizações de ESS precisam ser coerentes com seus valores, potencializando-os dentro da ESS e também no restante da sociedade. De maneira distinta ao pensamento neoclássico, que percebe o ser humano apenas como homem econômico, a ESS, por sua vez, o considera um ser multifacetado, entretanto, não isento de apresentar discriminação de gênero em razão das influências do contexto social e cultural em que está inserido. As estruturas familiares e da sociedade acabam sendo reproduzidas no âmbito da ESS e essa é uma discussão ainda muito tênue na ESS. Além disso, é importante cuidar porque essa divisão sexual do trabalho pode configurar que o pleno emprego é para os homens e a economia social e solidária é para as mulheres, dado ao tipo de atividade que estas desempenham (NOBRE, 2003; BONET; MORENO, 2004; HILLENKAMP; GUÉRIN; VERSCHUUR, 2016). Segue Julie Matthaei (2010, p.76, tradução nossa) sobre esse cuidado de não reproduzir as estruturas da sociedade atual:

À medida que a economia solidária continua a crescer no contexto da atual crise transversal (financeira, energética, alimentar, climática, de pobreza), é 
crucial que economistas e teóricas feministas estejam presentes para combater as tendências masculinistas no movimento da economia solidária e criticar a dominação masculina das instituições.

Isabelle Hillenkamp, Isabelle Guérin, Christine Verschuur (2016) afirmam que de maneira geral, apesar de serem majoritárias em muitas iniciativas (artesanato, agricultura, culinária, costura, entre outras), as mulheres são sub-representadas. Quintela (2006) reforça esse pensamento ao destacar que, apesar da grande participação feminina, os documentos oficiais não fazem referências especificamente, ao trabalho das mulheres, e também não explicitam as perspectivas de gênero em seus objetivos. Autores apontam que as mulheres precisam contar com uma rede de apoio de parentescos e vizinhança, bem como creches e escolas para deixarem os filhos para poderem atuar nos empreendimentos solidários. Ou seja, apesar da configuração do movimento de preocupação com a igualdade, ainda se reproduz a divisão sexual do trabalho, uma vez que os maridos e companheiros praticamente não atuam nessa tarefa ( $7 \%$ somente), e em relação ao próprio movimento, a percepção é de que não há estrutura para essa tarefa durante a atuação das mulheres (apenas 4\% afirmam ter estrutura).

Santos (2010), Hillenkamp, Guérin, Verschuur (2016) e Matthaei (2010) reiteram essa necessidade de considerar a contribuição das mulheres que, apesar de importante, como mostrado acima, ainda não é muito debatida dentro das pesquisas e do próprio movimento, não são temas incorporados às agendas políticas, o que pode suscitar uma necessidade maior de aproximação com a economia feminista. Questões essenciais como entender se as mulheres ao ingressar na ESS acabam por encontrar uma possibilidade para sua emancipação ou se a solidariedade acaba auxiliando na reprodução de mecanismos de exploração, reflexões teóricas sobre o trabalho das mulheres, estendendo para análises das relações interpessoais, bem como a divisão das tarefas domésticas, é crucial para desvelar esse outro olhar sobre a economia.

Hillenkamp, Guérin, Verschuur (2016) destacam que não há ainda, dentro da ESS, uma preocupação em relação à reflexão sobre algumas categorias de análise da economia feminista, como por exemplo relacionar produção/reprodução da economia feminista com os princípios de reciprocidade, de redistribuição, de mercado e de autossuficiência da ESS. Além disso, as ações estão sempre conexas aos aspectos de autonomia e transformação social, porém muito pouco associadas com as questões relativas a uma economia plural como a ESS se apresenta, ou seja, o caráter econômico das ações ainda não é destacado.

Porém, Aguayo e Ramírez (2019, p. 5, tradução nossa) afirmam que 
fica claro como ambos os corpos teóricos - economia feminista e economia solidária - enfatizam a questão das necessidades humanas versus a utilidade ou lucro. A análise econômica feminista observou a organização do trabalho familiar em relação à satisfação coletiva das necessidades, enquanto as premissas da economia solidária levam essa questão à escala comunitária e social, onde o trabalho é distribuído através de hierarquias sociais e de gênero. $E[\ldots]$

Díaz (2009) acrescenta que tanto a economia feminista quanto a ESS possuem, portanto, uma visão crítica ao sistema hegemônico constituída em demandas justas, que subsidiam conceitualmente, as interpretações de processos e políticas concretas, além de promover alternativas fundamentadas nas características culturais e históricas de cada comunidade.

Aguayo e Ramírez, (2019, p. 9, tradução nossa) finalizam afirmando que "é dessa opção epistemológica que escolhemos olhar para elas [as mulheres da ESS]: focar em suas possibilidades políticas e econômicas ao invés de cegar nossos olhos com lentes escuras para focar nos limites"

Assim, é possível perceber as potencialidades de uma associação entre a ESS e a economia feminista pelos seus postulados que buscam perceber a sociedade para além do mercado, numa perspectiva multidimensional, tirando da invisibilidade as mulheres e suas atividades nem sempre econômicas, mas mercantis e/ou não monetárias.

A partir dessa aproximação entre essas duas outras formas de entender a economia, reforça-se a ideia de que um outro paradigma é necessário para abarcar essa maneira distinta de entender a sociedade com aspectos diversos que não exclusivamente o mercado.

\section{ELABORANDO ALGUMAS CONSIDERAÇÕES}

A partir do exposto anteriormente, é possível refletir sobre alguns aspectos importantes de nossa sociedade atual e as possibilidades de um entendimento ampliado e como a aproximação entre os temas tratados até o momento poderá ser frutífera para o avanço dos estudos.

Guerreiro Ramos (1989) traz a reflexão das atividades tidas como superiores no período pré mercado e consolidadas, pós revolução industrial, na forma de trabalho assalariado que passa a ser gratificante à medida que é desejado pelos pares. Essas atividades excluem conceitualmente as desempenhadas pelas mulheres que ou detinham 
subempregos ou que ficavam "apenas" com as tarefas domésticas e inferiores, uma vez que não eram remuneradas e, portanto, não gratificantes, não almejadas pelos demais.

Esse pensamento, consolidado pela economia tradicional, invisibiliza uma série de atividades realizadas ao entender que a sociedade é unidimensional, com a centralidade no mercado. As ações não mercantis e não monetárias não são consideradas nesse escopo, ou se o são, é de maneira marginal. E quem são as sujeitas predominantes nesse tipo de atividade? As mulheres que têm que dividir seu tempo entre os cuidados da casa e da família com o sustento dessa mesma família. E ao não conseguir (e muitas vezes nem ser considerada para tal) se dedicar exclusivamente ao trabalho formal, de mercado atividade superior -, é relegada à condição de subcategoria. As ações realizadas por elas, como dito anteriormente, são basilares para a reprodução da força de trabalho e para a manutenção da casa e dos familiares, são preponderantemente atividades não mercantis ou não monetárias. Não são consideradas nos sistemas de avaliação do mercado, tais como o produto interno bruto.

Este comportamento foi sendo assimilado ao longo do tempo e reforçado pela ciência, filosofia e religiões. Guerreiro Ramos (1989) desenvolve o pensamento da síndrome comportamentalista, ou seja, os indivíduos interiorizam padrões cognitivos sem perceber e passam a se comportar e conformar com determinados critérios, ordens e costumes, neste caso estabelecidos pela sociedade centrada no mercado, unidimensional que valoriza determinadas atividades em detrimento de outras e consequentemente, determinados sujeitos em detrimento de outros. Assim, o homo economicus passa a ser tido como a entidade central e referência para essa sociedade, ou melhor, o que eram características e normas particulares de apenas um sistema social passam a ser confundidos com regras e normas de conduta geral.

Novamente, a construção desse paradigma centrado em critérios unidimensionais, que desconsidera a amplitude de possibilidades da vida humana foi uma construção histórica e cultural que acabou por reforçar a distinção entre homens e mulheres para além dos aspectos biofísicos. Essa mesma construção reforça a distinção apontada por Boaventura Santos (2010) da sociedade dividida entre "um lado da linha" e "outro lado da linha", ou seja, aqueles que desempenham as atividades consideradas relevantes para a manutenção da sociedade centrada no mercado estão de "um lado da linha" e os demais que não atuam em "atividades superiores", apesar de serem essenciais para a manutenção dessa estrutura centrada no mercado, estão do "outro lado da linha", na invisibilidade. Com isso, as atividades não mercantis e não monetárias, de cuidado, de afeto, de sustentação 
da vida, desenvolvidas basicamente pelas mulheres são omitidas deste paradigma unidimensional.

Portanto, faz-se necessário rever essa elaboração e passar a considerar os aspectos políticos, sociais, ecológicos e, com isso, dar luz às figuras até então desconsideradas, bem como suas ações.

Por isso, o paradigma paraeconômico parece ser pertinente a essa tentativa de ampliar as dimensões analisadas/percebidas pela sociedade. Ao se estruturar como um sistema multicêntrico que contempla outros aspectos da sociedade que não apenas o econômico, apesar de entender a importância dele, o paradigma se mostra como uma possibilidade ao permitir que todos que compõem a sociedade possam ter sua atuação considerada e valorizada. Da maneira como ele é estruturado a divisão "um lado da linha" e "outro lado da linha" perde sentido, uma vez que tira a centralidade do mercado e amplia as potencialidades analíticas e, portanto, destaca todas as ações realizadas sejam sociais, políticas, mercantis e não mercantis. Parece ser um potencial analítico para os estudos que tratam de outros aspectos ou de "outras economias" como a feminista e a social e solidária que buscam dar primazia também às atividades não mercantis e não monetárias consequentemente, elevando o papel da mulher nessas análises e, por conseguinte, na sociedade.

Nesse sentido, as análises e práticas das economias feministas e social e solidária podem ser de grande contribuição para esse repensar.

Os conceitos da sociedade multicêntrica e ESS associam-se, a partir do momento que ambos entendem que não pode haver uma primazia do econômico sobre as demais característica da sociedade. A sociedade multicêntrica, assim como a ESS, valoriza aspectos para além do econômico, uma economia plural que articula as dimensões econômica, sociais, políticas, culturais e ambientais de outra maneira. A combinação destas duas ideias promove um ganho teórico e prático para ambos os conceitos, uma vez que se pode estudar o que acontece nos empreendimentos sociais e solidários, a partir de uma visão multicêntrica de sociedade - ganham ambos.

As mulheres, como apontado anteriormente, são as "primeiras atrizes" da ESS e desse modo, podem ter suas ações contempladas nesse novo paradigma sem estar numa condição de subalternidade ou invisibilidade, ou do "outro lado da linha". Suas atividades neste contexto, a despeito de serem muitas vezes não monetárias e não mercantis, podem ser consideradas fortemente para a composição dessa sociedade multicêntrica, uma vez que não há a primazia do mercado. Esta mudança de referência pode permitir que elas 
rompam com a síndrome comportamentalista ao não mais se conformarem com os limites impostos pela sociedade atual, rompendo com a "linha" imposta por ele.

Além disso, a ESS é importante para essa reflexão como um espaço que impulsiona esse processo de mudança, apesar de suas contradições e limitações práticas, por ser um movimento com muita diversidade, pois congrega, em seus quadros, vários tipos de pessoas, provenientes de realidades socioeconômicas distintas, com objetivos os mais diferentes (complemento de renda, subsistência, outra forma de perceber o mundo, etc.), com perspectivas de atuação também diversas. Essa amplitude que o movimento oferece é muito valiosa para o desenvolvimento de uma outra percepção da sociedade, e para o incremento dos estudos, seja da própria ESS, da economia feminista, e de uma sociedade multicêntrica.

A economia feminista, por sua vez, de acordo com Carrasco (1999, p. 22) possui

Um objetivo ... claro: pretende-se reconceitualizar aquelas categorias nada neutras com as quais se define, se mede e se estuda a economia além de desenvolver novas perspectivas e novas formas de ver o mundo social e econômico que permitam tornar visível o que tradicionalmente a disciplina mantém como oculto: o trabalho familiar doméstico e suas relações com o que se constitui seu objeto de estudo, a produção e a troca mercantil.

Do mesmo modo que a ESS, a economia feminista tem como cerne de suas reflexões a preocupação com a unidimensionalidade da sociedade atual e as consequências disto diretamente na atuação das mulheres. Em suas várias vertentes, destaca a importância das atividades do cuidado, do afeto, da sustentação da vida, da reprodução, atividades basicamente não monetárias e não mercantis e, portanto, desconsideradas nesse contexto. Ao não terem visibilidade no mercado - centro de referência - passam a assumir uma condição subalterna, passam a se comportar, se conformar com o "outro lado da linha" e, obviamente, a reforçar a distinção entre atividades superiores e inferiores, sujeitos superiores e inferiores.

As análises da economia feminista destacam a importância de se refletir sobre as necessidades humanas que não se restringem a bens e serviços, realçando as necessidades de afetos e cuidados, que por isso, não podem ser marginalizadas pelas análises econômicas. Desse modo, a economia feminista propõe que a noção de trabalho seja ampliada e incorpore estas atividades fundamentais para o processo de sustentabilidade humana, porém não apenas reforçando a precarização do trabalho e a sustentação dessa vertente hegemônica. Portanto, a lógica mercantil preponderante 
precisa ser alterada criando alternativas para se perceber o mundo e o paradigma paraeconômico propõe especificamente, essa revisão dos sistemas sociais, numa perspectiva multicêntrica da sociedade em que nenhum enclave tem preponderância sobre os demais.

As reflexões indicadas neste trabalho propõem uma aproximação entre as percepções de mundo de Boaventura Santos com suas linhas divisórias da sociedade, a sociedade multicêntrica configurada pelo paradigma paraeconômico de Guerreiro Ramos e as "outras economias" como a social e solidária e a feminista que trazem para o cerne das discussões aspectos não considerados no paradigma hegemônico. Estas análises, ao dar uma nova centralidade na discussão das atividades mercantis, não mercantis e não monetárias, preocupam-se com a alteração do lugar das mulheres nesse cenário. Entendese que ao se pensar num novo paradigma, numa nova maneira de se perceber a sociedade sem "linhas" marcando lados, mas num movimento constante, que contemple as necessidades de todos os indivíduos, o caráter invisível do trabalho da mulher, marcadamente o trabalho doméstico, de cuidado e de sustentação da vida, poderá deixar de existir.

Resgatando, é possível perceber a contribuição da economia feminista e ESS para o paradigma paraeconômico pelo questionamento à centralidade do mercado que ambas criticam. O paradigma paraeconômico por sua vez, ao propor que se contemplem nas análises elementos para além do econômico, dá visibilidade para outros aspectos até então desconsiderados pela unidimensionalidade da visão de mercado, numa construção androcêntrica de sociedade, como o trabalho da mulher, o trabalho não mercantil e não monetário, em consonância com a ESS e a economia feminista. A economia feminista reforça a ESS ao trazer para este espaço as críticas à condição de inferioridade das mulheres muitas vezes reproduzida no interior dos empreendimentos e que também não se apresentam como um tema relevante nas discussões do movimento. A ESS, por seu turno, ao se apresentar como um espaço de relações mais equânimes possibilita à economia feminista um espaço profícuo para destacar as atividades não mercantis e não monetárias das mulheres e, consequentemente, fortalecer o movimento, encabeçado pela economia feminista, de dar relevância a esse trabalho. Retornando assim, ao paradigma paraeconômico que se consolida numa sociedade multicêntrica que considera os interesses e as necessidades de todos que a compõe.

Como sugestão para trabalhos futuros, a partir da aproximação proposta nesse estudo, é possível pensar que a economia feminista possa se apoiar no paradigma 
paraeconômico como estruturante de suas análises e, desse modo, desenvolver pesquisas propositivas de ações nas isonomias e fenonomias, por exemplo. Esse poderia ser o tema de um novo estudo, qual seja, como a economia feminista se desenvolve nas isonomias e fenonomias buscando perceber se há nesses espaços, dada as suas configurações, um caráter menos androcêntrico de atuação. Outra possibilidade, dentro da aproximação entre economia feminista e a ESS nesse paradigma, é desenvolver, em alguns empreendimentos mistos, ações que esclareçam os membros das críticas ao androcentrismo e à centralidade do mercado e como isso influencia na participação feminina, e acompanhar ao longo de um período as mudanças (ou não) ocasionadas e as consequências, tanto para as mulheres como para o próprio empreendimento, a partir de valores para além do econômico. Dessa maneira, as aproximações teóricas aqui propostas poderão ganhar desmembramentos práticos em outras pesquisas fomentando novas discussões.

\section{REFERÊNCIAS}

AGUAYO, Beatriz Eugenia Cid; RAMÍREZ, Loreto Patricia Arias. La Economía Solidaria en la politización del trabajo escondido de las mujeres. Revista Estudos Feministas, v. 27, n. 2, p. 1-12, 2019.

ARAÚJO, Geyson E. F. Caracterização da economia solidária à luz do ambiente isonômico de Guerreiro Ramos: um estudo no grupo mulheres decididas a vencer. 2010. Dissertação (Mestrado em Administração) - Universidade Federal do Rio Grande do Norte, Centro de Ciências Socioeconômicas, Natal, 2010.

AZEVEDO, Ariston; ALBERNAZ, Renata O. A Paraeconomia como modelo e paradigma para a análise e a formulação de políticas públicas: o resgate de uma possibilidade.

EmTese, Vol. 2, n. 1 (2), p. 20-32, jan - jun, 2004.

BELLE, François. Executivas: quais as diferenças na diferença? In: CHANLAT, J.F. (coord.). 0 indivíduo na organização, v 2. São Paulo: Atlas, 2010.

BONET, Maria Antonia Ribas; MORENO, Antonia Sajardo. La desigual participación de hombres y mujeres en la economía social: teorías explicativas La desigual participación de hombres y mujeres en la economía social: teorías explicativas. Revista Ciriec Espanha, v. 50, p. 77-103, 2004.

BULGACOV, Yara L. M.; CASTIGLIA, Felipe Z. Dialogando com os princípios de uma abordagem substantiva das organizações. Revista Psicologia, Organizações e Trabalho (rPOT), v. 3, n. 2, p. 1-34, jul./dez 2003.

CARRASCO, Cristina (org). Introdução para uma economia feminista. In: CARRASCO, C. (org.) Mujeres y economía. Barcelona: Icaria, 1999. 
CHANLAT, Jean François. Ciências sociais e management: reconciliando o econômico e o social. São Paul: Atlas,1999.

DIAZ, Natalia. Economias feminista, social y solidaria. Respuestas heterodoxas a la crisis de reproducción en América Latina. ICONOS - Revista de Ciencias Sociales, n. 33, v. 12, pp. 77-89, 2009.

FRANÇA FILHO, Genauto. Terceiro Setor, economia social, economia solidária e economia popular. Bahia Análise \& Dados, v. 12, n. 1, p. 9- 19, jun. 2002.

FRANÇA FILHO, Genauto. A temática da economia solidária e suas implicações originais para o campo dos estudos organizacionais. RAP, Rio de Janeiro, v. 37, n. 1, p. 11-31, jan./fev. 2003.

FRANÇA FILHO, Genauto C. Decifrando a noção de paraeconomia em Guerreiro Ramos: a atualidade de sua proposição. O\&S, v. 17, n. 52, p. 175-197, jan-mar, 2010.

FERNANDEZ, Brena Paula Magno. Economia feminista: metodologias, problemas de pesquisa e propostas teóricas em prol da igualdade de gêneros. Revista de Economia Política, v. 38, n. 3, p. 559-583, 2018. Disponível em:

$<$ http://www.scielo.br/scielo.php?script=sci_arttext\&pid=S0101$31572018000300559 \&$ Ing=pt\&tlng=pt> Acesso em 10/02/2020.

GRECCO, Fabiana Sanches. O viés androcêntrico da ciência econômica e as críticas feministas ao homo economicus. Temáticas, v. 26, n. 52, p. 105-134, 2018.

GRECCO, Fabiana Sanches; FURNO, Juliane Costa; TEIXEIRA, Marilane Oliveira. Por uma ciência econômica feminista. Temáticas, v. 26, n. 52, p. 11-22, 2018.

GUÉRIN, Isabelle. As mulheres e a economia solidária. São Paulo: Loyola, 2005.

GUERREIRO RAMOS, Alberto. A nova ciência das organizações. Rio de Janeiro, Ed. da Fundação Getulio Vargas, 1989.

HILLENKAMP, Isabelle; GUÉRIN, Isabelle; VERSCHUUR, Christine. A economia solidária e as teorias feministas: possíveis caminhos para uma convergência necessária. Debates Feministas - SOF, n. 03, p. 1-34, 2016.

LAVILLE, Jean Louis; GAIGER, Luis Inácio. Economia solidária. In: HESPANHA et al. (Coord.). Dicionário internacional da outra economia. Coimbra: Almedina, 2009.

LECHAT, Noelle Marie P. Economia social, solidária, terceiro setor: do que se trata? Civitas, ano 2, n. 1, p. 123-140jun. 2002.

LISBOA, Armando de M. Economia solidária: incubando uma outra sociedade. Proposta, n. 97, p. $50-58,2003$.

LISBOA, Armando de M. Economia solidária e autogestão: imprecisão e limites, RAE, p. 109-115, jul./set. 2009. 
MATTHAEI, Julie. Más allá del hombre económico: crisis cconómica, economía feminista, y la economía solidária. Cayapa. Revista Venezolana de Economía Social, vol. 10, n. 19, pp. 65-80, 2010.

NOBRE, Miriam. Introdução à economia feminista. Economia Feminista - SOF, p. 1-4, 2002.

NOBRE, Miriam. Diálogos entre economia solidária e economia feminista. IN: FARIA, Nalu e NOBRE, Miriam (orgs). A produção do viver: ensaios de economia feminista. São Paulo: SOF Cadernos Feministas, 2003.

NOBRE, Miriam. Interação entre economia feminista e economia solidária nas experiências de grupos de mulheres. Sempre Viva Organização Feminista - SOF, p. 111, 2014.

NOBRE, Miriam. Economía solidaria y economía feminista: elementos para una agenda. Red de Economía Alternativa y Solidaria Euskadi, n. 4. 2015.

PAULA, Ana Paula Paes. Guerreiro Ramos: resgatando o pensamento de um sociólogo crítico das organizações. O\&S, v. 14, n. 40, p. 169-188, jan./mar. 2007

PESSOA, Cleudes; RAMOS, Jeanette Filomeno Pouchain; PEIXOTO, Socorro Letícia Fenandes. Economia solidária e feminista: reflexões em torno da autonomia econômica das mulheres. http://www. fbes. org. br/, 2004. Acesso em 06/02/2020.

QUINTELA, Sandra. Economia Feminista e Economia Solidária: sinais de outra economia. Instituto Políticas Alternativas para o Cone Sul - PACS. v.5, 2006.

SANTOS, Boaventura de Sousa. Para além do pensamento abissal: das linhas globais a uma ecologia de saberes. In: SANTOS, B. S.; MENESES, M. P. (orgs.). Epistemologias do sul. São Paulo: Cortez, 2010.

SANTOS, Graciete. Economia Solidária e Feminista: um encontro possível. Cadernos Feministas de Economia e Política, 2010. Disponível em:

$<$ https://fbes.org.br/download/economia-solidaria-e-feminista/> Acesso em 06/02/2020.

SAUVAGE, Patrice S. OCDE: réconcilier l'économique et le social - vers une économie plurielle. Paris: OCDE, 1996.

SPECHT, Analine Almeida. Economia Feminista. Cadernos Brasil Local:

Desenvolvimento e Economia Solidária, v. Suplemento, n. 2009, p. 4-12, 2009.

TEIXEIRA, Marilane Oliveira. A economia feminista e a crítica ao paradigma econômico predominante. Temáticas, v. 26, n. 52, p. 135-166, 2018. 